\title{
Reforma Psiquiátrica e Inclusão Social: um Estudo com Familiares de Doentes Mentais
}

\author{
Psychiatric Reform and Social Inclusion: \\ a Study with Mental Patients' Relatives
}

Reforma Psiquiátrica e Inclusión Social: un Estudio con Familiares de Enfermos Mentales

Silvana Carneiro Maciel, Daniela Ribeiro Barros, Antonia Oliveira Silva \& Leoncio Camino

Universidade Federal da Paraíba

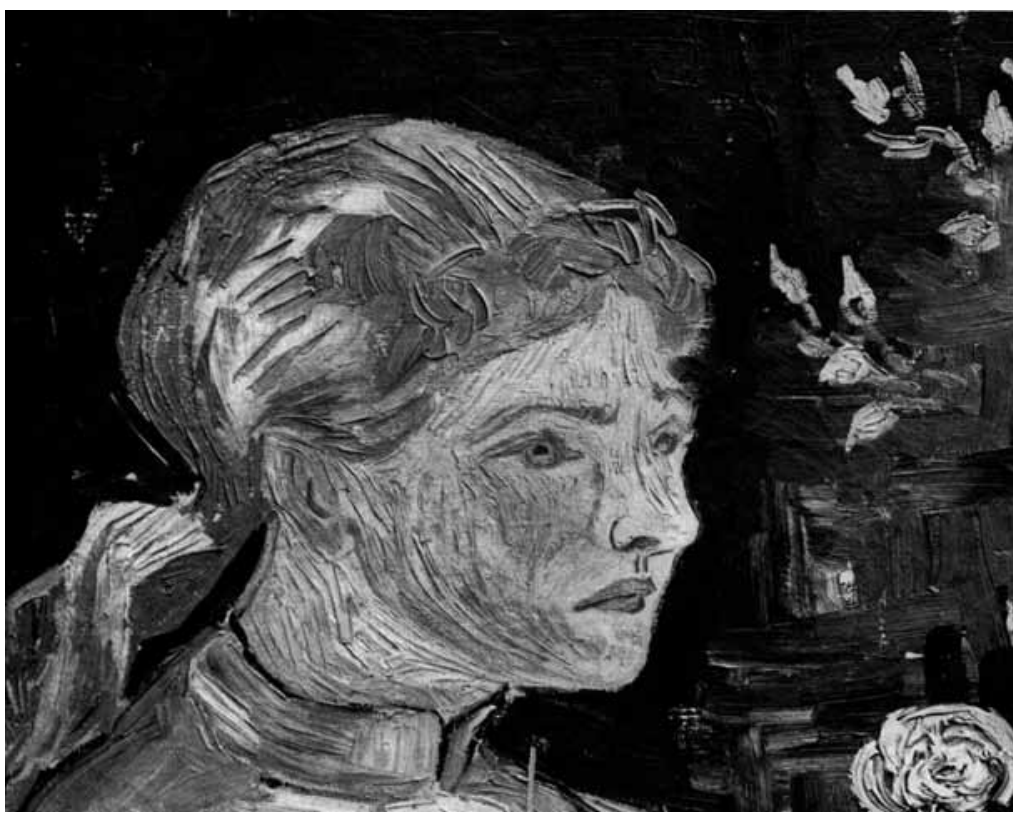


Resumo: A reforma psiquiátrica é um processo em construção, não ocorrendo de forma consensual em todo o mundo. Está relacionada às particularidades das condições econômicas, históricas, políticas e culturais que caracterizam as diferentes regiões e países. Enquanto prática social, é construída coletivamente, sendo composta por profissionais, familiares e usuários e pela sociedade em geral. O presente estudo visa a analisar os significados atribuídos por familiares de doentes mentais à família, à família do doente mental e à inclusão social no atual contexto da reforma psiquiátrica. Foi realizado em João Pessoa, na Paraíba, com 60 familiares de doentes mentais atendidos em um hospital psiquiátrico e em uma unidade do Centro de Atenção Psicossocial (CAPS). Para a coleta de dados, utilizou-se o Teste de Associação Livre de Palavras, que foi analisado pelo software Tri-Deux-Mots. Os resultados revelaram que a família do doente mental cnsidera possuir atribuições como preconceito, sobrecarga, tristeza e sofrimento, o que constitui um sério empecilho para a inclusão sociofamiliar do doente mental, dificultando assim a aceitação da reforma psiquiátrica e de seus pressupostos.

Palavras-chave: Reforma psiquiátrica. Família do doente mental. Hospital psiquiátrico. Inclusão social.

Abstract: The psychiatric reform is a growing process which does not occur in a consensual way throughout the world. It is related to the peculiarities of economic, historical, political and cultural conditions that characterize the different regions and countries. As a social practice, it is formed by a collective way, including professionals, relatives, users and the society as a whole. The present work aims to analyse the significance given by the relatives of mental patients to the families of mental patients and the social inclusion in the present context of the psychiatric reform. The work took place in João Pessoa, Paraíba, and involved 60 relatives of mental patients who were attended in a psychiatric hospital and in a unit of the Psychosocial Attention Center (CAPS). The data were collected by the Free Association of Words Test which was analyzed through the Tri-Deux-Mots software. The results showed that the mental patient`s families considers they have attributions such as prejudice, overload, unhappiness and suffering, which constitute a great obstacle to the social and familiar inclusion of the mental patient, hindering the acceptance of the psychiatric revolution and its tenets.

Keywords: Psychiatric reform. Mental patient's family. Psychiatric hospital. Social inclusion.

Resumen: La reforma psiquiátrica es un proceso en construcción, no ocurriendo de forma consensual en todo el mundo. Está relacionada a las particularidades de las condiciones económicas, históricas, políticas y culturales que caracterizan las diferentes regiones y países. Mientras la práctica social, es construida colectivamente, siendo compuesta por profesionales, familiares y usuarios y por la sociedad en general. El presente estudio pretende analizar los significados atribuidos por familiares de enfermos mentales a la familia, a la familia del enfermo mental y a la inclusión social en el contexto actual de la reforma psiquiátrica. Fue realizado en João Pessoa, en Paraíba, con 60 familiares de enfermos mentales atendidos en un hospital psiquiátrico y en una unidad del Centro de Atención Psicosocial (CAPS). Para la recogida de datos, se utilizó la Prueba de Asociación Libre de Palabras, que fue analizada por el software Tri-DeuxMots. Los resultados revelaron que la familia del enfermo mental considera tener atribuciones como prejuicio, recargo, tristeza y sufrimiento, lo que constituye un serio obstáculo para la inclusión sociofamiliar del enfermo mental, dificultando así la aceptación de la reforma psiquiátrica y de sus conjeturas.

Palabras clave: Reforma psiquiátrica. Familia del enfermo mental. Hospital psiquiátrico. Inclusión social.

À medida que a eficácia das instituições asilares passou a ser questionada, surgiram diversos movimentos que se refletiram na reforma psiquiátrica, a qual consiste em um processo em construção, no Brasil e no mundo, e não ocorre de forma consensual ou homogênea (Oliveira, 2002). Está relacionada às condições econômicas, históricas, políticas e culturais que caracterizam as diferentes regiões e países, determinando as práticas singulares. Pode ser entendida como um movimento social, articulada a um conjunto de iniciativas operadas nos campos legislativo, jurídico, administrativo e cultural, que visam a transformar a relação entre a sociedade e a loucura. Enquanto prática social, esse movimento é construído coletivamente, nas diferenças, nos conflitos e nas contradições. Como todo movimento social, apresenta 
Macêdo e Jorge (2000) afirmam que, com o processo de reforma e com a modernização da assistência, surgiu a proposta de equipe multiprofissional. uma composição heterogênea, incluindo profissionais, familiares, usuários e a sociedade em geral, englobando o Movimento Social por uma Sociedade sem Manicômios, a Associação de Usuários e Familiares, partidos políticos, igrejas e organizações nãogovernamentais, entre outros (Amarante, 1995).

Historiando o Movimento da Reforma Psiquiátrica, observa-se que as três últimas décadas constituíram momentos de efervescência conceitual-filosófica, com implicações diretas no cuidado ao doente mental. Conforme relatam Colvero e Machado (2000), os anos 70 foram marcados por debates sobre os direitos humanos dos pacientes psiquiátricos reclusos em manicômios. Várias denúncias sobre maustratos e falta de assistência começaram a surgir na mídia, criando condições favoráveis à motivação da opinião pública e de certos políticos sobre as questões da atenção à saúde mental.

Contemporaneamente, a reforma psiquiátrica surgiu no sentido de questionar a instituição asilar e a prática médica e de humanizar a assistência, fazendo com que houvesse ênfase na reabilitação ativa e na inclusão social, em detrimento da custódia e da segregação. Foram criados, então, novos serviços de atenção à saúde mental. Macêdo e Jorge (2000) afirmam que, com o processo de reforma e com a modernização da assistência, surgiu a proposta de equipe multiprofissional. Nessa proposta, o saber e o poder aparecem diluídos, mais bem distribuídos, articulandose à noção de multiplicidade dos problemas e à necessidade de diferentes terapias, inserindo também o apoio e a orientação à família.

Contudo, a criação de "novos" serviços de atenção não significa necessariamente a transformação da lógica manicomial e da forma de compreender e praticar a psiquiatria. Como alerta Oliveira (2000), pode-se correr o risco de se desenvolver práticas antigas com nova roupagem, seja por desconhecimento dos profissionais, seja pela filosofia de serviço:

Para que, de fato, um serviço desenvolva práticas ancoradas na reforma psiquiátrica, é preciso que essas instituições se configurem enquanto produção de saberes, de convivência, de invenção da saúde, respaldadas em um novo paradigma, compreendendo o doente como sujeito, com necessidades, com capacidades, com possibilidades, com desejos e com direitos, abandonando a relação com o doente "perigoso e incapaz", como "sujeito fora de si", passando a relacionar-se com o cidadão. (p. 58)

Seguindo esse raciocínio, Giovanella e Amarante (1994) lembram que o aparato manicomial não é o hospital psiquiátrico, embora seja a mais expressiva instituição onde se exercita o isolamento do doente mental. O aparato manicomial é o conjunto de gestos, olhares e atitudes, que fundam limites e intolerâncias às diferenças. Em grande parte, esses limites e intolerâncias são informados pelo saber psiquiátrico, existente de forma radicalizada no hospício, mas presente também em outras modalidades assistenciais e no cotidiano das relações sociais.

Dessa forma, Costa-Rosa (2000) destaca que, para haver mudança radical em relação ao modo asilar, não basta que haja variações nos dispositivos institucionais, é necessário que eles superem qualitativa e quantitativamente os recursos asilares e que se estruturem segundo uma "lógica" oposta à do hospital psiquiátrico: a lógica da desospitaliazação e da inclusão socio-familiar.

No entanto, apesar de todas as lutas na esfera político-ideológica e também das várias inovações teórico-técnicas efetivadas para superar o modo asilar, ainda se pode observar a dominância do modelo hospitalocêntrico. Esse modelo considera a 
Barros (2003)

destaca que, ao representar uma política instituída pelos serviços de saúde mental, a desospitalização e a inclusão social devem considerar tanto os aspectos subjetivos dos pacientes quanto o universo social e cultural no qual se encontram. relação com a loucura em termos de cura, continuando no mesmo campo ideológico tradicional que a identifica com a doença mental.

No Brasil, a partir dos anos 1980, ocorreram muitas modificações no sentido de procurar transformar a relação da sociedade com a loucura, que está cristalizada no asilo e na exclusão social. Foram criados serviços "alternativos" aos manicômios e realizadas reformas dos asilos e dos ambulatórios. Mas, embora essas experiências fossem ricas, de um modo geral, não tiveram impacto significativo sobre a qualidade da assistência e pouco contribuíram para a mudança da hegemonia hospitalar e das representações acerca da doença mental.

No campo legislativo, foi aprovado pelo Congresso Nacional e sancionado pelo Presidente da República, em 2001, o Projeto de Lei $n$ o 3.657/89, que se transformou na Lei no 10.216, de 06 de abril de 2001, de autoria do deputado Paulo Delgado (PT-MG). Essa lei dispõe sobre a extinção progressiva dos manicômios e a sua substituição por novas modalidades de atendimento, como hospitais-dia, Centro de Atenção Psicossocial (CAPS) e lares protegidos. Propõe a substituição gradativa dos leitos em hospitais especializados e dificulta a internação psiquiátrica involuntária, detonando um processo de discussão no País sobre as formas mais adequadas de atenção em saúde mental. Isso levou a Coordenação de Saúde Mental do Ministério da Saúde a abrir financiamento para outras modalidades de assistência, que representam alternativas à internação tradicional, tais como: centros de convivência, Núcleos de Atenção Psicossocial (NAPS), CAPS, hospitais-dia, emergências psiquiátricas, alas psiquiátricas em hospitais gerais, lares e albergues abrigados e oficinas, entre outras. Tais modalidades de serviços requerem prioridade para a clientela de risco em psiquiatria e apontam práticas profissionais mais diversificadas, incluindo a comunidade e a família.

Barros (2003) destaca que, ao representar uma política instituída pelos serviços de saúde mental, a desospitalização e a inclusão social devem considerar tanto os aspectos subjetivos dos pacientes quanto o universo social e cultural no qual se encontram. Portanto, pretender a transformação da instituição psiquiátrica sem considerar as portas de sustentação que a própria sociedade the oferece é recair na ilusão de que, pela técnica, seria possível modificar a realidade.

É justamente isso o que está ocorrendo no Brasil: a desospitalização e a inclusão sociofamiliar do doente mental sem a consideração da família, da sociedade e das portas de sustentação da exclusão. No Brasil, houve um desmonte dos hospitais psiquiátricos para economizar recursos financeiros, sem que houvesse a instalação de uma rede alternativa suficiente e de qualidade para atender toda a demanda da saúde mental e sem a preparação da sociedade e da família para a inclusão sociofamiliar dos doentes mentais. Satanizaram o hospital como centro de maus-tratos e torturas, e desativaram muitos ambulatórios dos programas de saúde pública. Capilarizaram os CAPS e desvirtuaram sua função, transformando-os num híbrido que ninguém sabe se é equipamento de atenção primária, secundária ou terciária. De acordo com Spinola (2006), a política de saúde mental descuidou-se da formulação de um sistema integrado, deixando de lado a necessária interação entre os cuidados primários, secundários e terciários.

O trabalho na comunidade e na família e a ênfase na prevenção primária exigem, entre outras coisas, uma equipe grande e qualificada. A comunidade e a família devem estar preparadas para receber e prestar 
assistência aos pacientes desospitalizados. Além disso, deve haver a criação de espaços de assistência extra-hospitalares em número suficiente para atender toda a população. Na realidade, ocorre o oposto. A centralização nos CAPS como eixo da reforma causou o esquecimento dos demais serviços comunitários de acolhida aos doentes mentais, como o resgate da cultura e da medicina popular, e de colocar não só a família mas toda a população como parte integrante do tratamento. Apesar de ser considerada importante e necessária, a reforma psiquiátrica, pelo modo como está sendo conduzida no Brasil, é desastrosa, e fica desacreditada pela família, pela sociedade e até pelos profissionais (Maciel, 2007).

Entretanto, as mudanças ocorridas nas realidades social, política, econômica e cultural que hoje impulsionam a reforma psiquiátrica não se deram ao acaso, senão com um movimento de revolução e de transformação, com repercussões na vida do doente mental, de sua família e da sociedade. Gonçalves e Sena (2001) afirmam que não há mais possibilidade de um recuo desse movimento, pois trata-se de um processo social, histórico e dinâmico, que já alcançou o sentido do novo. A negação do manicômio já convive com os serviços substitutivos e com a inclusão socio-familiar do doente mental, sendo essa uma nova realidade, que exige a criação de novas formas de cuidar do doente mental. Contudo, está ocorrendo um grande choque entre as propostas da reforma psiquiátrica e a devolução ou a manutenção do doente mental na família e na sociedade. O doente mental está sendo entregue à família e a sociedade sem que se tenha o devido conhecimento de suas reais necessidades e condições, em termos materiais, psicossociais, de saúde e de qualidade de vida.

Analisando tal questão, de acordo com o relatório da Organização Pan-Americana da Saúde/Organização Mundial da Saúde
(OPAS/OMS, 2001), em muitos países em desenvolvimento, como o Brasil, as famílias desempenham papel-chave na atenção aos mentalmente enfermos e são, em muitos aspectos, as provedoras primárias de atenção. Com o gradual fechamento dos hospitais psiquiátricos, o impacto na família pode ser positivo ou negativo, dependendo da compreensão, do conhecimento, das aptidões e da capacidade de dar atenção ao familiar afetado por transtorno mental. Por essas razões, uma importante estratégia, baseada na comunidade, é ajudar as famílias a compreender as doenças, estimular a adesão ao tratamento, reconhecer os primeiros sinais de recorrência e assegurar a pronta resolução de crises.

O isolamento do paciente e a custódia psiquiátrica permaneceram por muito tempo, e necessitam, na atualidade, de uma reestruturação das crenças e das representações da família acerca do tratamento, pautada no novo modelo de saúde mental, advindo com a reforma psiquiátrica, a desinstitucionalização da loucura e a inclusão sociofamiliar. A família apreendeu o discurso do século XIX, de que o tratamento da doença mental se faz pelos médicos e pela hospitalização. Durante séculos, o doente foi retirado da família e postulou-se que ele precisava ser cuidado por quem sabia cuidar e tinha o "saber e a cura" - os médicos -, e em local adequado e isolado, separado da família e da sociedade - o hospital. Agora, depois de sedimentadas essas representações, defendese a volta do paciente para o lar e para a sociedade, com adesão à reforma psiquiátrica e à inclusão social, com a desconstrução de todas essas representações e práticas. Assim, faz-se necessário observar como as famílias de doentes mentais interpretam essa nova situação.

É preciso, portanto, repensar a forma como estão sendo efetivadas a reforma psiquiátrica, a desospitalização e a inclusão sociofamiliar do doente mental. 
A Lei preconiza o fechamento de leitos psiquiátricos e o enfoque no tratamento extra-hospitalar, com a inclusão do doente na família, através do programa De Volta para Casa. Contudo, alguns estudos, como os de Vilela (1984), Birman e Serra (1988), Gonçalves e Sena (2001), Melman (2001), Maciel (2007), Maciel, Maciel, Barros, Sá e Camino (2008), demonstram que a família ainda não está preparada para arcar com a responsabilidade do tratamento e assumir esse novo papel.

Decorre daí a importância de se tomar os familiares como objeto de estudo. Além do interesse teórico sobre a temática, existem necessidades práticas, derivadas dos programas de saúde mental, na medida em que tais programas têm atribuído papel relevante à interação família-sociedade, com vistas à inclusão social.

Com base nessas questões, a presente pesquisa teve o objetivo de analisar como os familiares de doentes mentais representam a família, a família do doente mental e a inclusão social. O intuito foi o de apreender como esses indivíduos, que constituem a base do processo da reforma psiquiátrica, estão representando essas questões e aceitando o processo de inclusão do portador de transtorno mental na família e na sociedade.

Buscou-se também verificar em que se assemelham e em que diferem as representações dos familiares de inserções diferentes (CAPS x hospital psiquiátrico), e em que ancoram as suas representações ao se posicionarem acerca da família, da família do doente mental e da inclusão social no atual contexto da reforma psiquiátrica.

\section{Trajetória metodológica}

-Este estudo foi realizado em instituição psiquiátrica particular, que atende pelo SUS, na cidade de João Pessoa (PB), em uma instituição pública de serviço substitutivo
(CAPS). A amostra foi composta de 30 familiares de cada grupo, perfazendo um total de 60 participantes (mães, esposas, pais, irmãos, filhos), de ambos os sexos (sendo $77 \%$ feminino e $33 \%$ masculino), com nível de escolaridade variado $(46,5 \%$, ensino fundamental/analfabeto; $42,5 \%$, ensino médio completo/incompleto e $7 \%$, ensino superior completo/incompleto) e idade superior a 18 anos (20,0\%, entre 2040 anos, e 80,0\%, acima de 40 anos). Foram selecionados para a amostra familiares de doentes mentais que conviviam na mesma residência e que possuíam laços econômicos, jurídicos, sociais e afetivos, considerandose os variados "arranjos familiares". Como critério de exclusão, foram eliminados da amostra familiares de pacientes que estavam em tratamento de dependência química e que, portanto, não tinham familiaridade com a doença mental.

Para a coleta dos dados, foi utilizado o Teste de Associação Livre de Palavras, com os seguintes estímulos indutores: família, família do doente mental e inclusão social, devendo os participantes associarem cinco palavras para cada estímulo. A aplicação foi feita individualmente, em uma sala da instituição (hospital psiquiátrico e CAPS), com a autorização dos participantes e a garantia do anonimato.

A pesquisa atendeu os requisitos da Resolução no 196/96, do Conselho Nacional de Saúde, que traça as diretrizes e as normas reguladoras de pesquisa que envolva seres humanos, tendo sido aprovada pelo Conselho de Bioética do Centro de Ciências Sociais da Universidade Federal da Paraíba (CCS/UFPB).

Para a análise dos dados, utilizou-se o software Tri-Deux-Mots, que representa graficamente as variações semânticas na organização do campo espacial, revelando aproximações e oposições das modalidades na construção dos fatores analisados através 
da análise fatorial de correspondência (AFC). Os dados coletados formaram um banco de dados, composto pelas variáveis fixas codificadas em números, seguidas das variáveis de opinião, ou palavras-resposta, emitidas pelos indivíduos com relação a todos os estímulos indutores, o que possibilitou a redução do seu volume em um menor número de fatores.

\section{Resultados}

Os dados representados na Figura 1 referem-se aos estímulos família (1), família do doente mental (2) e inclusão social (3). O espaço fatorial, constituído por dois fatores (F1 e F2) e delimitado pelas respostas aos estímulos indutores, revela a existência de agrupamentos representacionais ou, como se denomina em estatística, de "nuvens". Essas "nuvens" evidenciam as semelhanças e as diferenças nos conteúdos e na estrutura das representações dos atores sociais

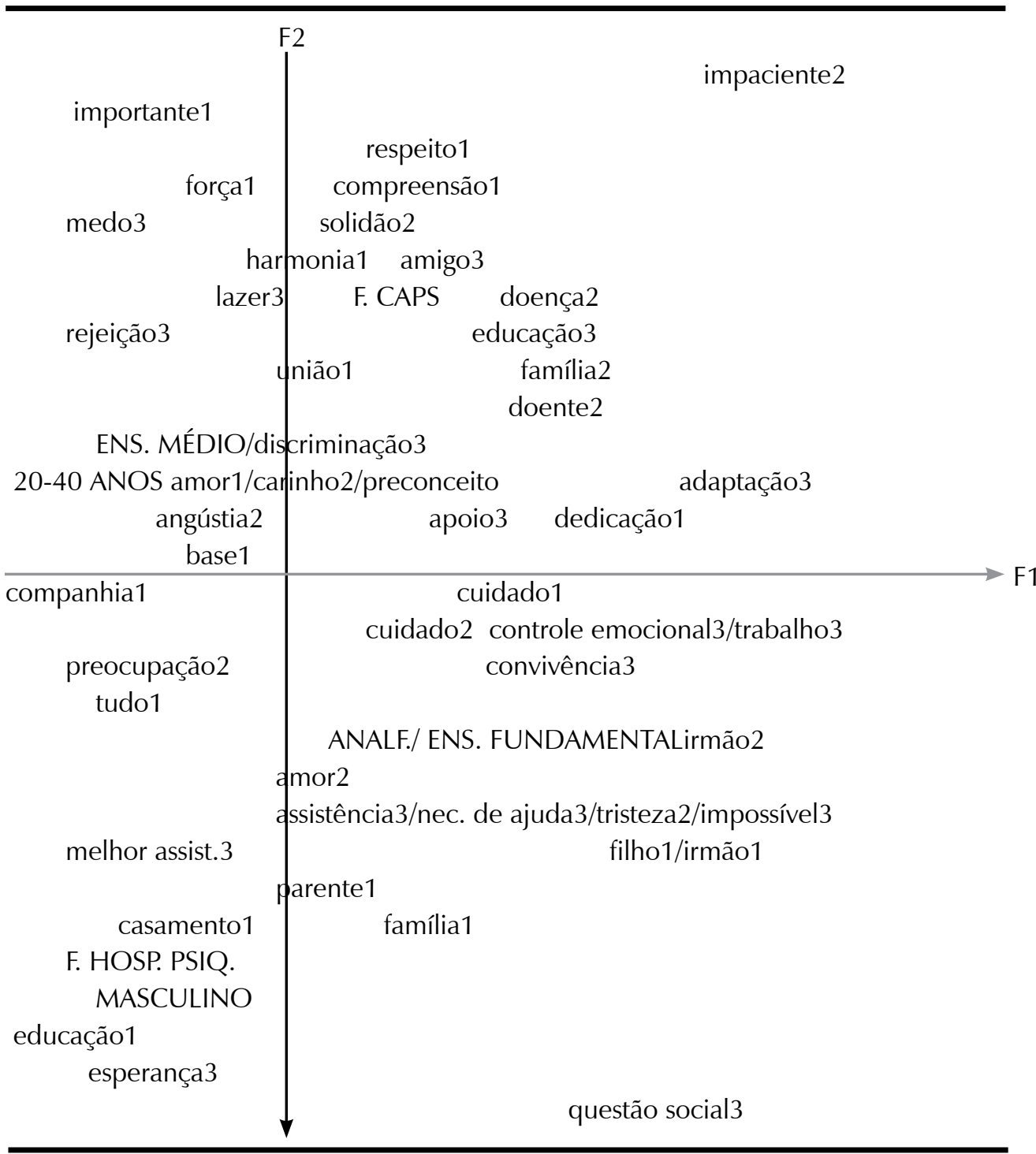

Figura 1. Plano fatorial de correspondência das representações acerca da família (1), da família do doente mental (2) e da inclusão social (3), produzidas pelos familiares de CAPS e de hospitais psiquiátricos. 
No primeiro fator (F1), na linha horizontal em cinza, encontram-se as representações de valor estatístico mais significativo, que explica $42,0 \%$ da variância total das respostas, enquanto o segundo fator (F2), na linha vertical em azul, representa 23,6\% da variância total das respostas. Pode-se verificar que a soma das variâncias perfaz um total de 65,6\%; desse modo, diz-se que, estatisticamente, os dados são significativos.

Pode-se observar a oposição entre as associações dos familiares do ensino médio/ idade 20-40 anos (quadrante superior esquerdo) e os familiares com nível de escolaridade de analfabeto/ensino fundamental (quadrante inferior direito). Da mesma forma, houve oposição entre as associações dos familiares de CAPS (quadrante superior direito) e os familiares de hospital psiquiátrico (quadrante inferior esquerdo).

Não houve diferenciação clara entre as representações dos grupos no que se refere à família (estímulo 1). Essas representações se mostraram mais consensuais e de cunho positivo, sendo a família associada a: importante, compreensão, educação, dedicação, carinho, cuidado, tudo, base, amor, força, união, harmonia, dentre outras representações como filho, casamento e irmão.

Também houve uma representação consensual entre os grupos sobre a família do doente mental (estímulo 2). Essa família também foi associada a questões positivas, como importante, responsável, carinho, cuidado e amor. Porém, na representação sobre a família do doente mental, surgem associações com conotações negativas, como preconceito, impaciente, solidão, doente, angústia, tristeza e preocupação, o que representa vivências de sofrimento e de sobrecarga familiar.

Com relação à inclusão social do doente mental (estímulo 3), observou-se, nesta pesquisa, uma diferenciação em relação aos familiares de CAPS, que têm uma visão mais positiva da inclusão, associada a apoio, a amigos, à educação, ao lazer e à adaptação. Os familiares de ensino médio, com idades que variavam de 20 a 40 anos, estabeleceram representações acerca da inclusão social com os significados de medo, rejeição e discriminação. No que diz respeito aos familiares com nível de escolaridade mais baixo e de hospitais psiquiátricos, também se observou uma representação mais negativa da inclusão social, com palavras como: trabalho, impossível, controle emocional, necessita de ajuda e questão social.

\section{Discutindo os resultados}

Melman (2001) destaca que, na sociedade moderna ocidental, os pais são exigidos e culpabilizados pela educação, pela formação e pelas anormalidades dos filhos. Eles devem gerar filhos fortes, saudáveis e preparados para o mercado de trabalho, sendo acusados, direta ou indiretamente, pelo adoecimento. Sublinha, ainda, que a sociedade ocidental investiu e idealizou intensamente o núcleo familiar, colocando a família no centro e definindo-a como responsável por aquilo de bom ou de ruim que acontece. Tais questões também surgiram na presente pesquisa, em que se observou que tanto os familiares de CAPS como os de hospital psiquiátrico representaram a família de forma positiva, idealizada e central, com associações do tipo: base, amor, tudo, força, união, harmonia, respeito, compreensão, dedicação, cuidado, educação e companhia. A família é vista como espaço obrigatório dos afetos e sentimentos, sendo responsabilizada quase que integralmente pela educação, pela formação, pela felicidade e pelo bem-estar dos seus integrantes/filhos.

Desse modo, a família é responsabilizada por qualquer anormalidade que possa romper o equilíbrio de seus familiares. O adoecimento do filho abala, de forma intensa, a autoestima dos pais, uma vez que o filho doente parece representar denúncias de falhas no 
sistema familiar, que não conduziu com sucesso a missão de formá-lo.

Com relação aos familiares de doentes mentais, Melman (2001) afirma que eles têm uma sobrecarga ainda maior, pois, além das responsabilidades naturalmente assumidas, também são vítimas de exclusão, de preconceito, de sentimentos de dor e de sofrimento, de forma que associam os sintomas da enfermidade a algo ruim. Há, ainda, o fato de que o surto psicótico de um parente rompe e desorganiza a vida da família, representando o colapso dos esforços e o atestado de incapacidade de cuidar adequadamente do outro.

Nos dados encontrados, essas questões foram corroboradas, observando-se que, ao representarem a família do doente mental, os familiares de CAPS e de hospital psiquiátrico a associam a representações positivas, mas que vêm imbuídas de obrigações e de responsabilidades, com atribuições do tipo: importante, responsável, educação, cuidado, amor e carinho. Mas também trazem representações de conotação negativa, impregnadas de sobrecarga e problemas emocionais advindas da convivência com o doente mental, surgindo associações como: preconceito, impaciente, solidão, preocupação, sofrimento, tristeza, doença e angústia. Acredita-se, com base em pesquisas como as de Melman (2001), Maciel (2007) e Maciel et al. (2008), que, ao se referirem ao preconceito, os familiares do doente mental não se colocam como preconceituosos, mas como vítimas de preconceitos da sociedade, o que justifica, assim, as representações supracitadas. As representações sobre o preconceito ancoram-se em vivências e sofrimentos a partir das interações sociais e das alterações comportamentais do portador de transtorno mental.

De acordo com o relatório da OPAS/OMS (2001), uma em cada quatro famílias tem pelo menos um membro que sofre de um transtorno mental ou comportamental.
Essas famílias vêem-se obrigadas não só a proporcionar apoio físico e emocional como também a arcar com o impacto negativo da estigmatização e da discriminação, que se fazem presentes. Os encargos que recaem sobre a família vão das dificuldades econômicas às reações emocionais, ao estresse em face de um comportamento perturbado à disrupção da rotina doméstica e à restrição das atividades sociais.

Por isso, além da carga direta em lidar com o doente mental, é preciso levar em conta as oportunidades perdidas. As famílias que têm um membro que possui distúrbio mental fazem diversos reajustes e assumem compromissos que impedem outros familiares de atingir o seu pleno potencial no trabalho, nas relações sociais e no lazer.

As famílias assumem o papel de dedicar considerável parcela do seu tempo para cuidar de um parente mentalmente enfermo e sofrem privações econômicas e sociais por não ser essa pessoa inteiramente produtiva. Há também o constante temor de que a recorrência da doença possa causar perturbação repentina e inesperada na vida dos membros da família.

Para Gonçalves e Sena (2001), um agravante a mais em relação aos familiares de doentes mentais diz respeito aos serviços de saúde. Muitas vezes, estes trabalham com uma representação de família idealizada, pressupondo que a família apresente condições de cuidar do seu doente e possa suprir todas as necessidades, inclusive emocionais. Com isso, esquecem-se do fato de que a família também precisa ser cuidada. Dessa maneira, pressupõem que a família tenha não só condições de cuidar do seu doente mental mas o dever de fazêlo, havendo a imposição do cuidado e a negação do sofrimento familiar. Contudo, os autores chamam a atenção para a sobrecarga que a família enfrenta na convivência com o doente mental, principalmente por ocasião da alta hospitalar. Nessa ocasião, são 
desencadeadas atitudes de incompreensão familiar e até de rejeição, motivadoras de reinternações sucessivas ou de internações prolongadas e até permanentes, dados esses também encontrados em pesquisas como as de Maciel (2007) e Maciel et al. (2008).

Observa-se, então, uma sobrecarga na família, que pode constituir uma das razões da permanência de altas taxas de reinternação no País, conforme apontam pesquisas na área, como as de Pasqualli, Martins e Martins (1987) e Bandeira (1993). De acordo com esses estudos, uma grande proporção de pacientes, depois de deixar o hospital e retornar ao ambiente sociofamiliar, acaba sendo reinternada.

Na realidade, a família do doente mental necessita da ajuda de profissionais da saúde mental, mas, na prática, não há efetivação desse trabalho. É comum que esses profissionais culpabilizem as famílias e exijam que aceitem a doença, sem oferecerlhes suporte nem orientação, interferindo, assim, na desospitalização e na inclusão sociofamiliar do doente mental, acima citados.

Essas questões podem justificar os dados encontrados nesta pesquisa, que demonstram que a inclusão do doente mental (na família e na sociedade) é vista com ressalvas pelos familiares, sendo associada a questões como educação, lazer, adaptação, medo, rejeição, discriminação, trabalho, impossível, questão social, controle emocional, melhor assistência e convivência.

A nova política de saúde mental e seus programas envolvem uma mudança nas práticas familiares, no sentido de, em vez de os familiares colocarem o doente no hospital "para obter sossego", passarem a "cuidar deles como membros plenos da família". Mas Tsu (1993) destaca que os familiares não estão aceitando o fechamento das instituições psiquiátricas nem recebendo com tranqüilidade a transferência de função, porque a família do doente mental não se encontra em condições de cuidar do paciente por questões financeiras e emocionais. Ressalta, ainda que os familiares ainda não assimilaram o novo discurso da saúde mental com ênfase na família e na sociedade; isso demonstra claramente a dificuldade dos familiares em aceitar a reforma psiquiátrica e a inclusão sociofamiliar.

Na realidade, concordamos com Gonçalves e Sena (2001) quando afirmam que a desospitalização e a inclusão sociofamiliar são duplamente perversas, porque atingem, sobretudo, o doente mental e a família, principalmente as mulheres, que são as cuidadoras. Esses dados também se assemelham aos coletados na presente pesquisa, em que se encontrou um percentual maior do sexo feminino (cuidadoras).

Analisando a dificuldade de implantação da reforma psiquiátrica e da inclusão sociofamiliar do doente mental, Vasconcelos (1992) afirma que, se compararmos as condições históricas brasileiras e globais relacionadas à emergência de programas de desinstitucionalização e aos pontos necessários para o sucesso desses programas -, ver-se-á que o quadro não é muito animador, e cita os seguintes motivos: elevada taxa de desemprego com poucas chances de atividades produtivas e socialmente valorizadas estarem disponíveis para a clientela de serviços de saúde mental; crise fiscal e organizativa do Estado e das políticas sociais e o fato de ainda não vivermos os efeitos de uma transição radical da estrutura familiar, de modo que o cuidado informal é basicamente prestado pela família e tem caráter matrifocal; esse também foi um dado encontrado na presente pesquisa.

Devido a essas questões, Gonçalves e Sena (2001) afirmam que não é mais aceitável reduzir a reforma psiquiátrica e a inclusão social ao fechamento dos hospitais e à 
devolução dos doentes às famílias, como se estas fossem, indistintamente, capazes de resolver a problemática de vida cotidiana sem levar em conta as dificuldades geradas pela convivência, pela manutenção e pelo cuidado com o doente mental.

\section{Considerações finais}

Em função das questões abordadas e dos dados analisados, pode-se afirmar que, apesar de ter tido início nos anos 1970, a reforma psiquiátrica ainda está iniciando sua caminhada, e esta não acontece de forma consensual. Isso ocorre em razão da complexidade temática, que envolve condições econômicas, históricas, políticas e culturais. Além disso, a reforma, entendida como um movimento social, é articulada a um conjunto de iniciativas operadas nos campos legislativo, jurídico, administrativo e cultural, que visam a transformar a relação entre a sociedade e a loucura, e que ainda não foram efetivadas.

Na verdade, nosso país avançou muito nos últimos anos na aprovação de leis garantidoras de direitos inspiradas pelo movimento em favor da humanização das instituições de atenção à saúde mental. Do ponto de vista institucional, temos razão de sobra para comemorar a emergência de novos instrumentos legais comprometidos com os direitos civis dos pacientes psiquiátricos. Mudanças importantes ocorreram, sim, e não podem ser subestimadas, mas não foram suficientes.

Com base nas pesquisas apresentadas, podemos afirmar que a família, por estar inserida na sociedade, acaba pactuando com os seus valores, crenças e representações sobre a doença mental, reproduzindo o discurso da sociedade, acrescida de suas vivências. Essas representações são acrescidas do desgaste emocional e do sofrimento familiar. Todas essas questões levam a uma sobrecarga, o que faz com que os familiares recorram à medicação (para controle dos sintomas) e à hospitalização (para alívio da sobrecarga), apresentando dificuldades na aceitação da reforma psiquiátrica e da inclusão sociofamiliar. Isso ocorre porque a família não se encontra em condições de cuidar do paciente, por razões não só financeiras mas também emocionais.

Por isso, faz-se necessário maior aprofundamento do trabalho com os familiares e com a sociedade, para que ocorra uma real aceitação do doente mental, ou seja, para que não aconteça uma "inclusão camaleônica": uma inclusão que esconde uma exclusão. Nesse sentido, devemse buscar práticas e discursos mais inclusivos, mais positivos e menos segregacionistas frente ao portador de doença mental.

Silvana Carneiro Maciel*

Doutora em Psicologia Social UFPB-UFRN; professora do Departamento de Psicologia da UFPB.

Daniela Ribeiro Barros

Mestre em Psicologia Social UFPB, professora da Faculdade Natalense para o Desenvolvimento do Rio Grande do Norte (FARN).

E-mail: danjulymonique@uol.com.br

\section{Antonia Oliveira Silva}

PhD pelo Instituto Superior de Ciências do Trabalho e da Empresa Portugal, professora do Departamento de Enfermagem da UFPB.

E-mail: alfaleda@hotmail.com

\section{Leoncio Camino}

PHD pela Universite Catholique de Louvain, professor do Departamento de Psicologia da UFPB.

E-mail: leocamino@uol.com.br

*Endereço para envio de correspondência:

Rua Vereador Gumercindo B. Dunda, 378/1401- Aeroclube, João Pessoa - PB - Brasil, CEP 58036-850

E-mail: silcamaciel@ig.com.br 


\section{Referências}

Amarante, P. (Org.). (1995). Loucos pela vida: a trajetória da reforma psiquiátrica no Brasil. Rio de Janeiro: FIOCRUZ.

Bandeira, M. (1993). Reinserção de doente mental na comunidade: fatores determinantes das re-hospitalizações. Jornal Brasileiro de Psiquiatria, 42(9), 491-498.

Barros, S. (2003). Ensino de enfermagem psiquiátrica e reabilitação psicossocial. In M. Jorge, W. Silva, \& F. Oliveira (Orgs.), Saúde mental: da prática psiquiátrica asilar ao $3^{\circ}$. Milênio (pp. 73-80). São Paulo: Jorge Lemos.

Birman, J., \& Costa, J. (1994). Organização de instituições para uma psiquiatria comunitária. In P. Amarante (Org.), Psiquiatria social e reforma psiquiátrica (pp. 41-72). Rio de Janeiro: FIOCRUZ.

Birman, J., \& Serra, A. (1988). Os descaminhos da subjetividade: um estudo da instituição psiquátrica no Brasil. Rio de Janeiro: EDUFF.

Lei $n^{\circ}$ 10216, de 06 de abril de 2001. (2001). Dispõe sobre a proteção e os direitos das pessoas portadoras de transtornos mentais e redireciona o modelo assistencial em saúde mental. Recuperado em 22 de abril de 2008, de http:// www.planalto.gov.br/ccivil_03/Leis/LEIS_2001/L10216.htm

Colvero, L., \& Machado, A. (2000). Cuidado da enfermagem em saúde mental: desafio da modernidade. In M. Jorge, W. Silva, \& F. Oliveira (Orgs.), Saúde mental: da prática psiquiátrica asilar ao $3^{\circ}$ milênio (pp. 67-71). São Paulo: Jorge Lemos.

Costa-Rosa, A. (2000). O modo psicossocial: um paradigma das práticas substitutivas ao modo asilar. In P. Amarante (Org.), Ensaios, subjetividade, saúde mental e sociedade (pp. 141-168). Rio de Janeiro: FIOCRUZ.

Desviat, M. (1999). A reforma psiquiátrica. Rio de Janeiro: FIOCRUZ.

Giovanella, L., \& Amarante, P. (1994). O enfoque estratégico do planejamento em saúde mental. In P. Amarante (Org.), Psiquiatria social e reforma psiquiátrica (pp. 113-148). Rio de Janeiro: FIOCRUZ.

Gonçalves, A., \& Sena, R. (2001). A reforma psiquiátrica no Brasil: contextualização e reflexos sobre o cuidado com o doente mental na família. Revista Latino-Americana de Enfermagem, 9(2), 32-47.
Macêdo, A., \& Jorge, M. (2000). Concepções de loucura e sua influência na prática psiquiátrica. In M. Jorge, M., W. Silva \& F. Oliveira (Orgs.), Saúde mental: da prática psiquiátrica asilar ao $3^{\circ}$ milênio (pp. 125-148). São Paulo: Jorge Lemos.

Maciel, S. C. (2007). Exclusão/inclusão social do doente mental/ louco: representações e práticas no contexto da reforma psiquiátrica. Tese de Doutorado, Universidade Federal da Paraíba, João Pessoa.

Maciel, S. C., Maciel, C. M. C., Barros, D. R., Sá, R. C. N., \& Camino, L. F. (2008). Exclusão social do doente mental: discursos e representações no contexto da reforma psiquiátrica. Psico-USF, 13(1), 115-124.

Melman, J. (2001). Família e doença mental: repensando a relação entre profissionais de saúde e familiares. São Paulo: Escrituras.

Oliveira, F. (2000). Reabilitação psicossocial no contexto da desinstitucionalização: utopias e incertezas. In M. Jorge, W. Silva, \& F. Oliveira (Orgs.), Saúde mental: da prática psiquiátrica asilar ao $3^{\circ}$ milênio (pp. 149-170). São Paulo: Jorge Lemos.

Oliveira, F. (2002). Construindo saberes e práticas em saúde mental. João Pessoa: Ed. UFPB.

Organização Pan-Americana da Saúde / Organização Mundial da Saúde. (2001). Relatório sobre a saúde no mundo. São Paulo: Gráfica Brasil.

Pasquali, L., Martins, A., \& Martins, F. (1987). Atitude frente ao doente mental: um modelo etiológico e medida de atitudes. Revista de Psicologia, 5(1), 37-67.

Souza, R., \& Scatena, C. (2005). Produção de sentidos acerca da família que convive com o doente mental. Revista Latinoamericana de Enfermagem, 13(2), 18-27.

Spinola, E. (2006). Editorial. Psiquiatria hospitalar: Departamento de Psiquiatria da Federação Brasileira de Hospitais, 3(3), $12-$ 15.

Tsu, T. (1993). A internação psiquiátrica e o drama dos familiares. São Paulo: EDUSP.

Vasconcelos, E. (1992). Do hospício à comunidade: mudanças sim, negligência não. Belo Horizonte: SEGRAC.

Vilela, M. (1984). Conhecimentos, opiniões, sentimentos e dificuldades de pacientes psiquiátricos em relação à alta hospitalar. Dissertação de Mestrado, Universidade Federal da Paraíba, João Pessoa. 